\title{
Preparation and Characteristics of Novel Fibers Based on Cellulose Acetate and Soy Lecithin for Attracting and Binding POPs
}

\author{
Jinxian Huo ${ }^{1}$, Zuopeng Li $^{1}$, Yin Wang² \\ ${ }^{1}$ School of Chemistry \& Environmental Engineering, Shanxi Datong University, Datong, China \\ ${ }^{2}$ The Key Laboratory of Water and Sediment Sciences, Ministry of Education, School of Environment, Beijing \\ Normal University, Beijing, China \\ Email: hjx511@163.com
}

Received August 2015

\begin{abstract}
Soy lecithin (SL)-modified cellulose acetate (L-CA) fibers for use as a novel biomimic material were prepared by a dry-jet wet spinning process from a solution of the polymer in dioxin. Characteristics of the L-CA fibers, such as structural properties, water absorbance, electrical conductivity and accumulation of trace persistent organic pollutants (POPs), were examined. Cross-sectional scanning electron microscopy (SEM) of L-CA unveiled a finger-like structure, along with a thin dense surface layer like that of CA. On the basis of X-ray photoelectron spectroscopic (XPS) observations, it was concluded that the enhancement of binding energy was optimum with $10 \%$ SL in the fiber, whereas superfluous SL led to self-assembly between the SL molecules, which weakened the binding between the SL and CA. Also, the L-CA fibers showed good water absorbance and a low charge conductivity in comparison to that of the non-modified CA fibers. Examination of the ability to accumulate POPs from water showed that L-CA is a effective candidate for the removal of micropollutants from aqueous solution.
\end{abstract}

\section{Keywords}

Biomimic Material, Dry-Jet Wet Spinning, Accumulation, Persistent Organic Pollutants

\section{Introduction}

In May 2009, parties to the Stockholm Convention on Persistent Organic Pollutants (POPs) agreed to add nine substances [1], to the 12 [2], already banned or restricted under the convention, which stimulated global efforts to eradicate these highly toxic chemicals from the environment. Requirements for the design of materials to be used to attract and bind trace POPs in water were put forward, including a high capacity for accumulation of POPs, non-toxicity, long lifetime and stability in water.

Two-phase and multi-phase materials have attracted worldwide attention due to their superior performance compared to that of traditional single-phase materials, among which bio-based composite materials offer benefits for a sustainable environmental strategy. In recent years, triolein was embedded into cellulose acetate (CA) 
membrane or other hydrophilic membrane to construct a functional substance with a high capacity $\left(10^{5}-10^{7}\right)$ for accumulating POPs [3]-[6]. Examination of the triolein-embedded CA membrane by cross-sectional scanning electron microscopy (SEM) showed a dispersion of triolein as micro-droplets in the membrane, which did not appear in the dense surface layer of the membrane; the number of triolein droplets increased gradually in a vertical direction beneath the surface layer [7]. The physically embedded triolein retains its high capacity for the accumulation of POPs. However, there is a marked phase separation of triolein in the membrane. If such materials are exposed to a harsh environment, such as meeting with a strongly external force or subjecting to a high temperature, trolein will leak out of the membrane.

Phospholipids, unlike neutral triolein, are a class of lipids that contain two hydrophobic glycerides, a negatively charged phosphate group and a positively charged choline molecule. The first identified phospholipid was lecithin, which can be obtained easily from readily available sources, such as soy beans and egg yolk and is used extensively for preparing biomaterials. Takashi Hasegawa [8] designed a polysulfone/2-methacryloyloxyethyl phosphorylcholine (MPC) membrane with MPC locating at the surface of the polysulfone. Sang Ho Ye [9], designed a CA membrane blended with poly (MPC)-co-n-butyl methacrylate (BMA) called PMB30 (MPC:BMA = 30/70 (mol\%)). Subsequently, he designed a CA hollow fiber membrane modified with PMB80 (MPC:BMA = 80/20 (mol\%)) [10]. PMB80 was coated on the surface in situ during the phase inversion of the dope solution by using a solution of PMB80 as an inner coagulant. Most research on phospholipid-contained materials is focused on artificial blood purification and the use of microcapsules as medicine. There are very few reports in the literature of phospholipid-containing materials being used for accumulating POPs.

Lecithin contains a neutral diglyceride and a polar head, which allows lecithin to interact with the polar groups in polymers, while two free hydrophobic glyceride chains are used specifically for accumulating POPs. It is possible that lecithin-containing materials are of greater stability and dispersity in a polymeric matrix than triolein-embedded materials.

Many polymers can be used as supports for lipids but hydrophilic polymers have better accessibility of soluble POPs to the surface of the materials. Cellulose and its derivatives are some of the most widely utilized natural materials [11]. CA is important because its water solubility coupled with hydrophobic groups enable it to be used in a number of aqueous processes [12], such as membrane separation [13]. CA exists in three types of structures in a polar solvent: a single CA chain, a dynamic structure or self-assembly formed temporarily and locally by the solvent-mediated hydrogen bonding between the intermolecular C-6 position hydroxyls of the anhydroglucose units in the CA backbone [14]. The positively charged choline may be electrostatically abstracted to carbonyl oxygen on CA, whereas a negatively charged phosphate group interacts with the hydroxyl group on CA by hydrogen bonding. The flexibility of the CA chain could lead to formation of sophisticated network structures that would enhance the immobilization of lecithin.

We used soy lecithin (SL) as a replacement for triolein and here we describe: (i) the preparation of fibers with different SL/CA ratios using a dry-jet wet spinning method [15]; (ii) a thorough characterization of the microstructure of L-CA fibers; (iii) the mechanism underlying the interaction between SL and CA; and (iv) electrical conductivity and the accumulation of POPs from water.

\section{Experimental Section}

\subsection{Materials and Instruments}

Cellulose acetate with 2.5 degrees of acetylation (DA) was purchased from the Chemical Reagent Corporation (Shanghai, China). SL was purchased from Sinopharm Chemical Reagent Beijing Co., Ltd. 1,4-Dioxane (AR) was used as the solvent and deionized water was used as the precipitating solution.

An environmental scanning electron microscope (ESEM; Quanta 200, FEI Co., Holland) equipped with an energy-dispersive X-ray microanalysis (EDAX) system was used to acquire cross-sectional images of the fibers and the content of elements $\mathrm{C}, \mathrm{N}, \mathrm{O}$ and $\mathrm{P}$ in different areas of the sample. The cross-section of the sample was prepared by freeze-fracture in liquid nitrogen. A GIKOIB-3 sputter coater with a gold-palladium target was used for coating gold onto the cross-sections.

IR spectra were obtained with a Spectrum FTIR-8400 system from Perkin-Elmer. The wave number was between $4000 \mathrm{~cm}^{-1}$ and $650 \mathrm{~cm}^{-1}$. Ultrathin film was prepared in order to improve transparency.

X-ray photoelectron spectroscopy (XPS) was done with an XSAM-800 spectrometer using an Al K $\alpha$ (1486.7 eV) X-ray source. To remove charging shifts and to cope with Fermi edge coupling problems, binding energies (BE) were scaled against the peak of the C-(C, H) component coming from contaminating carbon (set to 284.6 
$\mathrm{eV}$ ). The pressure inside the analysis chamber was $<2 \times 10^{-8} \mathrm{~Pa}$. The C1s, O1s, N1s and P2p spectra were recorded, and surface atomic compositions were determined.

A cyclic voltammogram (CV) was obtained to assess the electrical conductivity using a 2500 A electrochemical system (Lanlike Co., China). The electrolytic solution was $0.005 \mathrm{~mol} \cdot \mathrm{L}^{-1}$ potassium ferricyanide and 0.1 $\mathrm{mol} \cdot \mathrm{L}^{-1}$ potassium chloride. A CA or L-CA film sample was coated onto the surface of a glassy carbon electrode (GCE) to make a working electrode.

A Varian 3800 gas chromatograph equipped with electron capture (GC-ECD) was used to test the accumulating performance for POPs in water. Analysis was done as described [7].

\subsection{Preparation of L-CA Fibers}

A simple and inexpensive solution-blending method was used to dissolve CA and SL [16]. First, the oxygen within 1,4-dioxane was removed by sparging with nitrogen. Then different SL contents (SL versus CA) and other additives were dissolved in $25 \mathrm{ml}$ of 1 ,4-dioxane at $50^{\circ} \mathrm{C}$. Subsequently, $5 \mathrm{~g}$ of CA was added and the mixture was kept at $80^{\circ} \mathrm{C}$ for 2 days with stirring to ensure uniform mixing of the viscous syrups with different SL/CA ratios.

Using constant nitrogen pressure as the driving force, the prepared syrups were extruded directly into the precipitating liquid (deionized water) after a transitory stay in air. As the white filaments emerged, they precipitated from the deionized water and solidified.

\section{Results and Discussion}

\subsection{Morphology of L-CA Fibers}

Figures 1(a)-(d) show ESEM micrographs of the L-CA fibers with different SL/CA ratios in 1,4-dioxane. All fibers presented finger-like apertures, which were slightly enlarged with increased SL loading. Figure 1(e) shows an image of fibers with a 1:10 SL/CA ratio, from which it was calculated that the thickness of the dense surface layer is $\sim 4 \mu \mathrm{m}$ and the external surface was full of holes of $\sim 0.1 \mu \mathrm{m}$ diameter. 1,4-Dioxane/water as solvent/non-solvent can cause instantaneous delamination of the CA membrane, which is an important mechanism for forming finger-like apertures [17]. The presence of apertures is disadvantageous for fiber membranes. So, another solvent/non-solvent mixture, tetrahydrofuran (THF)/water, was investigated. The experimental results showed that a sponge-like structure was formed (Figure 1(f)).

\subsection{Miscibility and Interaction between SL and CA}

In order to investigate the miscibility of SL and CA, the content of the elements $\mathrm{C}, \mathrm{O}$ and $\mathrm{P}$ in different areas was measured by EDAX for the inner micro-areas and by XPS for the surface elements and the results are given in Table 1. The distribution of $\mathrm{C}$ and $\mathrm{O}$ is basically uniform in the center and in the sub-layer of the pure CA fiber. The presence of $\mathrm{P}$ can be due to impurity in the polymer or the solvent. The distribution of $\mathrm{C}$ and $\mathrm{O}$ and the $\mathrm{C} / \mathrm{O}$ ratio at the surface is different from that in the inner areas. The content of $\mathrm{P}$ in the center of the L-CA fiber is very similar to that in the sub-layer, which indicates a uniform distribution of SL in the L-CA fiber. Analysis of the P content at the L-CA surface, in the CA surface and within the L-CA, revealed that the P content attributed to addition of SL is basically the same as that within L-CA; i.e. SL is distributed uniformly at the surface and within the L-CA fiber.

Table 1. Elements' content in different micro-area of fibers (wt\%).

\begin{tabular}{ccccccc}
\hline & Selected micro-area & C & O & P & C/O \\
\hline \multirow{2}{*}{ CA } & Center & 80.26 & 19.61 & 0.13 & 4.09 \\
& Sub-layer & 81.20 & 18.70 & 0.10 & 4.34 \\
& Surface & 77.25 & 15.13 & 1.02 & 5.10 \\
& Center & 87.36 & 12.08 & 0.55 & 7.23 \\
& Sub-layer & 87.11 & 12.42 & 0.48 & 7.01 \\
& Surface & 78.06 & 15.09 & 1.77 & 5.17 \\
\hline
\end{tabular}




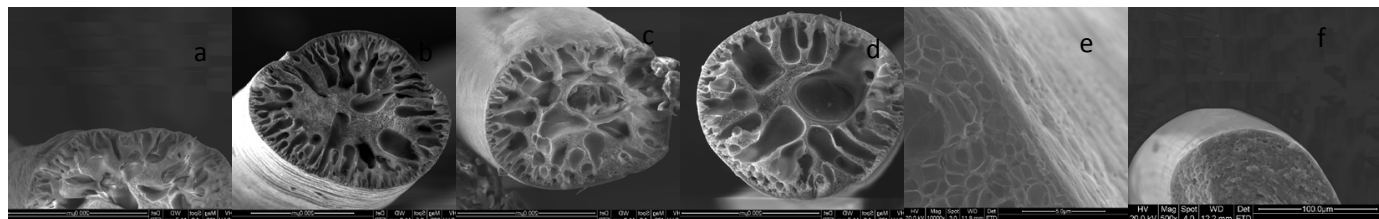

(a)

(b)

(c)

(d)

(e)

(f)

Figure 1. ESEM images of cross section of fibers with different soy lecithin/cellulose acetate ratio using 1, 4-dioxane as solvent (a) 0; (b) 1:50; (c) 1:20; (d) 1:10; (e) magnified image near the surface in order to clearly show dense layer.

The possibility of an interaction between SL and CA was investigated by examining the FT-IR spectra (Figure 2). We compared the spectrum of native CA with that of L-CA and found that the stretching vibration absorption peak of $\mathrm{C}=\mathrm{O}\left(\mathrm{CH}_{3} \mathrm{CO}\right)$ of CA shifts from $1754.94 \mathrm{~cm}^{-1}$ to $1752.42 \mathrm{~cm}^{-1}$, the peak of C-O (carboxylate) shifts from $1238.13 \mathrm{~cm}^{-1}$ to $1234.38 \mathrm{~cm}^{-1}$ and the peak of $\mathrm{C}=\mathrm{O}$ (COO) shifts from $1635.95 \mathrm{~cm}^{-1}$ to 1234.38 $\mathrm{cm}^{-1}$. The peak positions of $\mathrm{CH}_{2}, \mathrm{CH}, \mathrm{C}-\mathrm{O}$ (bridge) and $\mathrm{C}-\mathrm{O}-\mathrm{C}$ (pyranose ring) are not changed, indicating that interaction occurs in the ester position of CA. Comparing the spectrum of native SL to that of L-CA shows that the transmittance peak at $1459.56 \mathrm{~cm}^{-1}$, which is assigned to the symmetric bending of $-\mathrm{CH}_{3}$ at $-\mathrm{N}\left(\mathrm{CH}_{3}\right)^{3+}$, disappears. This is attributed to the electrostatic abstraction between $\mathrm{N}$ of SL and $\mathrm{C}=\mathrm{O}$ of $\mathrm{CA}$. The transmittance peak at $1230.62 \mathrm{~cm}^{-1}$ that is assigned to the stretching vibration of $\mathrm{P}=\mathrm{O}$ shifts from $1230.62 \mathrm{~cm}^{-1}$ to 1234.38 $\mathrm{cm}^{-1}$. The transmittance peak at $1065.49 \mathrm{~cm}^{-1}$, which is assigned to the stretching vibration of R-O-P-O-R', shifts from $1065.49 \mathrm{~cm}^{-1}$ to $1051.36 \mathrm{~cm}^{-1}$. These results indicate that negatively charged $\mathrm{O}$ connected to $\mathrm{P}$ interacts with the hydroxyl group of CA by hydrogen bonding.

Subsequently, XPS was measured support the identification of interaction sites by FT-IR analysis. The binding energies of C1s, O1s, P2p, N1s in CA, SL and L-CA fibers are given in Table 2. The C1s peak was resolved by using a least-squares peak-fitting program and the results revealed four chemical shifts: $\mathrm{C}$ connected to another $\mathrm{C}$ or $\mathrm{H}\left(\mathrm{C}-\mathrm{C}^{*} \mathrm{H}_{2}-\mathrm{C}\right)$; $\mathrm{C}$ is connected to a non-carbonyl $\mathrm{O}\left(-\mathrm{C}^{*} \mathrm{H}_{2}-\mathrm{O}\right)$; $\mathrm{C}$ is connected to two non-carbonyl $\mathrm{O}$ atoms (O-C*-O); C connected to a carbonyl $\mathrm{O}$ and to a non-carbonyl $\mathrm{O}\left(\mathrm{II}_{-\mathrm{C}_{-}} \mathrm{O}\right)$. The binding energy of $\|_{-C^{*}}$ O is increased by $0.19 \mathrm{eV}$, whereas the binding energies of other species are not changed. The fitting for O1s revealed two chemical shifts; i.e. an $\mathrm{O}$ is connected to a $\mathrm{C}$ by a single bond (-C-O*-) and an $\mathrm{O}$ is connected to a $\mathrm{C}$ by a double bond $\stackrel{\mathrm{O}_{-\mathrm{C}}-\mathrm{O}}{\mathrm{I}}$ and the binding energies are increased by $0.4 \mathrm{eV}$ and $0.367 \mathrm{eV}$, respectively.

The binding energies of P2p and N1s are increased by $0.405 \mathrm{eV}$ and $0.298 \mathrm{eV}$, respectively. According to the results of the analysis described above, SL and CA can effectively interact by electrostatic abstraction between the choline on SL and the carbonyl group on CA and by a hydrogen bond between the phosphoric group on SL and a hydroxyl group on CA. This confirmed that our hypothesis about the interaction is correct; SL can be immobilized stably on CA by this interaction.

\subsection{Voltammetry of CA Film and L-CA Film}

Water is a complex matrix that can contain a large number of ionized substances, substances with redox capacity or microorganisms capable of degradating L-CA fiber. It is possible that these substances interact with L-CA fiber by ion transport or electron transport, accordingly affect the chemical structure of L-CA fiber. It is salutary to study the electrical conductivity and electron transport ability of composite fibers in order to understand the interaction between various matters in water and composite fibers. Figure 3(a) shows a CV of an aqueous solution containing $0.005 \mathrm{~mol} \cdot \mathrm{L}^{-1} \mathrm{~K}_{3}\left[\mathrm{Fe}(\mathrm{CN})_{6}\right]$ with $0.1 \mathrm{~mol} \cdot \mathrm{L}^{-1} \mathrm{KCl}$ as the supporting electrolyte, showing a chemically reversible voltammetric process:

$$
E_{\mathrm{obs}}=\left(E_{p}^{r e d}+E_{p}^{o x}\right) / 2=0.1031 \mathrm{~V}(\Delta E=0.1094 \mathrm{~V})
$$




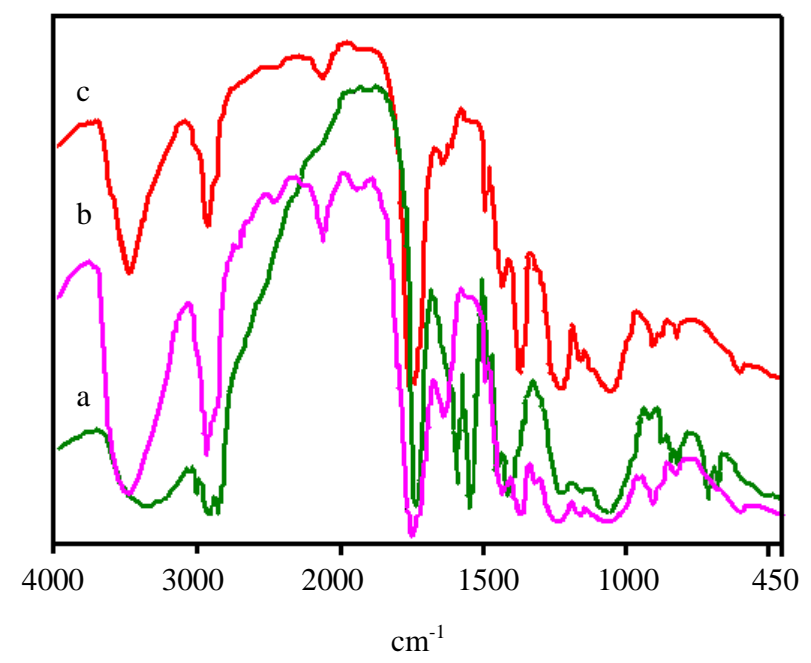

Figure 2. FT-IR spectra of SL, CA and L-CA, donated by a, b, c, respectively.

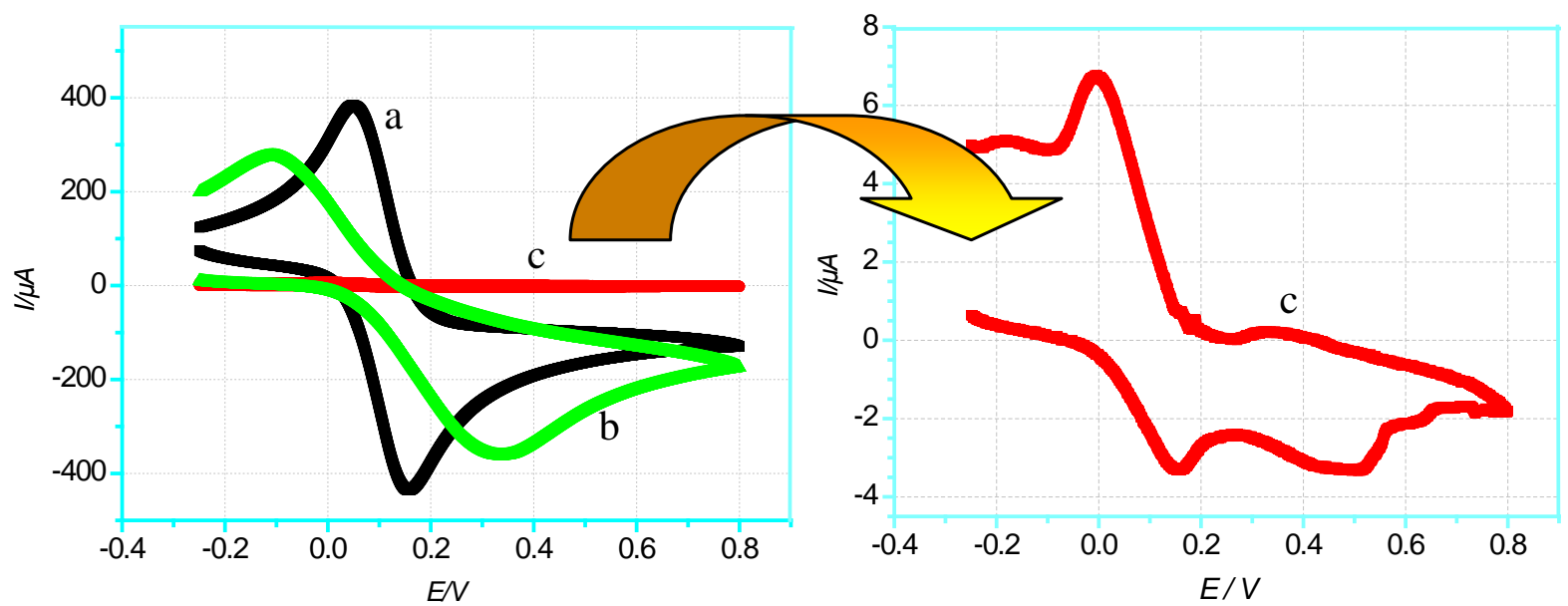

Figure 3. Cyclic voltamograms recorded on GCE modified by different thin films in the presence of $0.1 \mathrm{~mol} / \mathrm{L} \mathrm{KCl}$ as the supporting electrolyte and of $0.005 \mathrm{~mol} / \mathrm{L} \mathrm{Fe}(\mathrm{CN}) 64$ - as redox probe: (a) naked GCE; (b) CA film; (c) L-CA film.

Table 2. Binding energies of C1s, O1s, P2p, N1s in CA and L-CA fibers.

\begin{tabular}{|c|c|c|c|c|}
\hline & \multicolumn{4}{|c|}{ C1s (eV) } \\
\hline & C-C & C-O-C & $\mathrm{O}-\mathrm{C}-\mathrm{O}$ & $\mathrm{COO}$ \\
\hline $\mathrm{CA}$ & 284.798 & 286.010 & 287.330 & 289.200 \\
\hline \multirow[t]{3}{*}{ L-CA } & 284.770 & 286.031 & 287.404 & 289.390 \\
\hline & \multicolumn{2}{|c|}{ O1s (eV) } & P2p (eV) & N1s $(e V)$ \\
\hline & C-O-C & $\mathrm{C}=\mathrm{O}$ & - & - \\
\hline SL & - & - & 134.091 & 401.202 \\
\hline CA & 532.890 & 531.660 & - & - \\
\hline L-CA & 533.290 & 532.027 & 134.496 & 401.500 \\
\hline
\end{tabular}


Due to the $\left[\mathrm{Fe}(\mathrm{CN})_{6}^{4-}\right] /\left[\mathrm{Fe}(\mathrm{CN})_{6}^{3-}\right]$ redox couple. When the GCE surface was coated with a CA film, the Faradaic current response observed for the voltammetrically induced $\left[\mathrm{Fe}(\mathrm{CN})_{6}^{4-}\right] /\left[\mathrm{Fe}(\mathrm{CN})_{6}^{3-}\right]$ transformation decrease (Figure 3(b)). Nevertheless, the presence of the Faradaic current indicated that electron transfer reactions were still occurring between $\left[\mathrm{Fe}(\mathrm{CN})_{6}^{4-}\right] /\left[\mathrm{Fe}(\mathrm{CN})_{6}^{3-}\right]$ and the CA-coated GCE surface. The decrease in Faradaic and capacitive current between the bare electrode and the GCE coated with the CA is due to either the presence of numerous finger-like holes in the CA that allow the aqueous solution to reach the electrode surface (resulting in a diminished number of electron transfer reactions to occur) or electron tunneling from specific sites on the electrode surface that have a reduced coverage of the CA film.

When the GCE was coated with SL-incorporated CA film, the current observed during voltammetric scanning of the $\left[\mathrm{Fe}(\mathrm{CN})_{6}^{4-}\right] /\left[\mathrm{Fe}(\mathrm{CN})_{6}^{3-}\right]$-containing solution was less than that observed with the CA film alone (Figure 3(c)), indicating that the incorporation of SL into CA further reduces electron transfer between the GCE and the solution phase species. Although the distribution of SL in CA is a non-bilayer structure, its reduction of the current is similar to that of SL bilayers or multilayers [18]. The SL bilayer membrane is nearly completely insulative [19].

For a CA-coated GCE, we found that a chemically reversible voltammetric process took place at $E_{\mathrm{obs}}=$ $0.1207 \mathrm{~V}, \Delta E=0.4310 \mathrm{~V}$ due to the $\left[\mathrm{Fe}(\mathrm{CN})_{6}^{4-}\right] /\left[\mathrm{Fe}(\mathrm{CN})_{6}^{3-}\right]$ redox couple, indicating widening of the potential separation between the cathodic and anodic peaks, which could be due to the acidic nature of CA [20]. The negatively charged $\left[\mathrm{Fe}(\mathrm{CN})_{6}^{4-}\right]$ or $\left[\mathrm{Fe}(\mathrm{CN})_{6}^{3-}\right]$ electrostatically attracted to the acidic site of CA caused an increase of activation overpotential that can force the charge transfer.

For an SL/CA-coated GCE, besides the chemically reversible voltammetric process at $E_{\text {obs }}=0.0669 \mathrm{~V}, \Delta E=$ $0.1754 \mathrm{~V}$ due to the $\left[\mathrm{Fe}(\mathrm{CN})_{6}^{4-}\right] /\left[\mathrm{Fe}(\mathrm{CN})_{6}^{3-}\right]$ redox couple, there were oxidation peaks at $E_{\mathrm{ox}}=0.5176 \mathrm{~V}$ and $E_{\mathrm{ox}}=0.6272 \mathrm{~V}$; the corresponding reduction peaks were at $E_{\text {red }}=-0.1856 \mathrm{~V}$ and $E_{\mathrm{red}}=0.3208 \mathrm{~V}$. The peak widening of the first redox potential is rather large. Keeping in mind the fact that the SL molecules are charged because they contain both a positive and a negative charge at the polar head [21], it is reasonable to assume that the positive side of the SL polar head is possibly the site involved in the chemical interactions with $\left[\mathrm{Fe}(\mathrm{CN})_{6}\right]^{4-}$. The second redox potential is more positive than that of $\left[\mathrm{Fe}(\mathrm{CN})_{6}^{4-}\right] /\left[\mathrm{Fe}(\mathrm{CN})_{6}^{3-}\right]$ on native GCE. Because the SL can be oxidized in the presence of oxygen [22], it is possible that the presence of a current leads to a self-redox reaction of SL.

\subsection{Accumulation of POPs from Water}

We used heptachlor, endrin, lindane, mirex, deldrin and perfluorooctane sulfonate (PFOS) as model pollutants of POPs and investigated the accumulation capacity of L-CA fibers with $0.1 \mathrm{~g}$ of finger-like and sponge-like structures using $200 \mathrm{ml}$ of aqueous solution containing $10 \mu \mathrm{g}$ of the target pollutant. As shown in Figure 4, the structure of the fiber affected the accumulation capacity and the sponge-like fiber appeared to have greater capacity than that of the finger-like fiber for all test pollutants. For heptachlor, endrin, lindane and deldrin, the accumulation equilibrium was achieved within $10 \mathrm{~h}$ with a high accumulation capacity. Accumulated equilibrium for PFOS was also achieved within $10 \mathrm{~h}$ but with low accumulation capacity, possibly due to the long-chain structure or to higher solubility in water than that for POPs mentioned above. For mirex, accumulation continued slowly during the whole accumulation period, showing an entirely different style of accumulation due to the large molecular mass and the high level of steric hindrance. This study showed that the kinetics of accumulation of POPs on the L-CA fiber is different for different types of POPs. Further study of the accumulation process will be needed if L-CA fiber is to be used for the removal of POPs during water treatment.

\section{Conclusion}

A novel environment-friendly composite fiber with biomimic function was prepared for removing trace POPs 

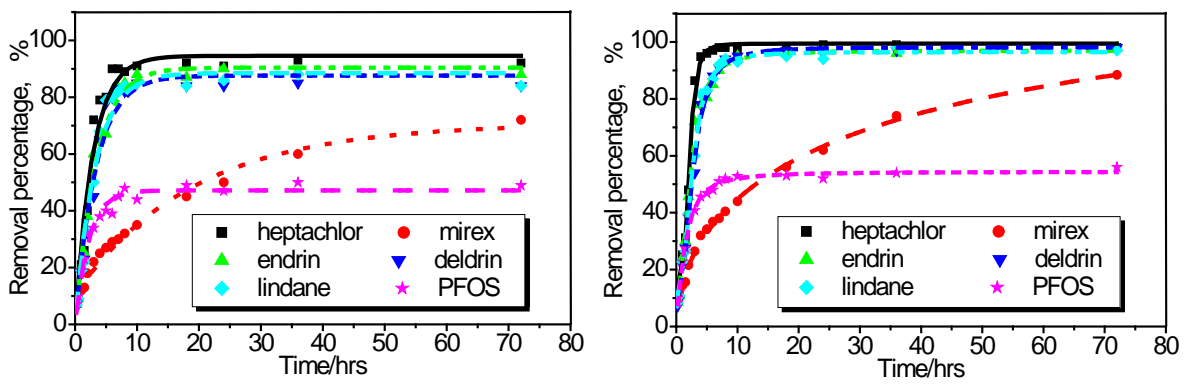

Figure 4. Accumulation curves for the selected POPs into the fibers over the 72 hrs equilibrium period: (left) finger-like fiber; (right) sponge-like fiber.

from water. The electrostatic force and the hydrogen bond between SL and CA caused distribution of SL in the CA fiber in a molecular state, improving the stability and the anti-stress characteristic of a composite fiber. Due to the good miscibility of SL and CA, they are both present on the surface of the fiber and are involved in the process of forming a dense surface layer. These results are different from those found for triolein in a CA film [7]. Addition of SL decreased the electron transport capacity, and it was found by cyclic voltammetry that substances with redox activity might react with SL. How the electrical properties of SL affect the accumulation performance is worthy of further study.

\section{Acknowledgements}

The authors gratefully acknowledge the funding of this study provided by the International Science \& Technology Cooperation Program of China (Grant No. 2013DFR90290) and the Shanxi Province Science Foundation for Youth (Grant No. 2012021006-1).

\section{References}

[1] Kohler, P.M. (2010) Chemicals Science for Policy: From Dirty Dozen to Toxic 21. 2010 Meeting of the International Studies Association. http://www.Allacademic.Com/meta/p_mla_apa_research_citation/4/1/3/4/5/p413452_index.html.

[2] Jansson, B. (2001) In International Symposium on Environmental Endocrine Disrupters, 2001. http://www.env.gojp/chemi/end/2001report/pdf-e/jansson-e.pdf

[3] Lv, Y.B. and Wang, Z.J. (2003) Accumulation of Organochlorinated Pesticides by Triolein-Containing Semipermeable Membrane Device (Triolein-SPMD) and Rainbow Trout. Water Res., 37, 2419-2425. http://dx.doi.org/10.1016/S0043-1354(03)00003-4

[4] Huo, J.X., Liu, H.J., Qu, J.H., Ru, J., Liu, H.N. and Li, G.T. (2005) Dieldrin and Endrin Removal from Water by Triolein-Embedded Adsorbent. Chinese Science Bulletin, 50, 2696-2700. http://dx.doi.org/10.1360/982005-471

[5] Ke, R.H., Xu, Y.P., Wang, Z.J., et al. (2006) Estimation of the Uptake Rate Constants for Polycyclic Aromatic Hydrocarbons Accumulated by Semipermeable Membrane Devices and Triolein-Embedded Cellulose Acetate Membranes. Environ. Sci. Technol., 40, 3906-3911. http://dx.doi.org/10.1021/es060493t

[6] Liu, H.J., Ru, J. and Qu, J.H. (2009) Removal of Persistent Organic Pollutants from Micro-Polluted Drinking Water by Triolein Embedded Absorbent. Bioresource Technol., 100, 2995-3002. http://dx.doi.org/10.1016/j.biortech.2009.01.026

[7] Huo, J.-X., Liu, H.-J., Qu, J.-H., et al. (2005) Preparation and Characteristic of Triolein-Embedded Composite Sorbents for Water Purification. Sep. Purif. Technol., 44, 37-43. http://dx.doi.org/10.1016/j.seppur.2004.12.001

[8] Takashi, H., Yasuhiko, I. and Kazuhiko, I. (2001) Preparation and Performance of Protein-Adsorption-Resistant Asymmetric Porous Membrane Composed of Polysulfone/Phospholipid Polymer Blend. Biomaterials, 22, 243-251. http://dx.doi.org/10.1016/S0142-9612(00)00180-0

[9] Ye, S.H., Watanabe, J., Iwasaki, Y. and Ishihara, K. (2003) Antifouling Blood Purification Membrane Composed of Cellulose Acetate and Phospholipid Polymer. Biomaterials, 24, 4143-4152. http://dx.doi.org/10.1016/S0142-9612(03)00296-5

[10] Ye, S.H., Watanabe, J., Iwasaki, Y. and Ishihara, K. (2005) In Situ Modification on Cellulose Acetate Hollow Fiber Membrane Modified with Phospholipid Polymer for Biomedical Application. J. Membrane Sci., 249, 133-141. http://dx.doi.org/10.1016/j.memsci.2004.10.006 
[11] Bochek, A.M. and Kalyuzhnaya, L.M. (2002) Interaction of Water with Cellulose and Cellulose Acetates as Influenced by the Hydrogen Bond System and Hydrophilic-Hydrophobic Balance of the Macromolecules. Macromol. Chem. Polym. Mater., 75, 989-993.

[12] Gómez-Bujedo, S., Fleury, E. and Vignon, M.R. (2004) Preparation of Cellouronic Acids and Partially Acetylated Cellouronic Acids by TEMPO/NaClO Oxidation of Water-Soluble Cellulose Acetate. Biomacromolecules, 5, 565-571. http://dx.doi.org/10.1021/bm034405y

[13] Wang, Y., Wang, Y.-J., Wang, L., et al. (2013) Reducing the Bioavailability of PCBs in Soil to Plant by Biochars Assessed with Triolein-Embedded Cellulose Acetate Membrane Technique. Environ. Environmental Pollution, 174, 250 256. http://dx.doi.org/10.1016/j.envpol.2012.12.004

[14] Tsunashima, Y., Kawanishi, H. and Horii, F. (2002) Reorganization of Dynamic Self-Assemblies of Cellulose Diacetate in Solution: Dynamical Critical-Like Fluctuations in the Lower Critical Solution Temperature System. Biomacromolecules, 3, 1276-1285. http://dx.doi.org/10.1021/bm0200682

[15] Zhang, X.F., Hua, H., Shen, X.Y. and Yang, Q. (2007) In Vitro Degradation and Biocompatibility of Poly(L-Lactic Acid)/Chitosan Fiber Composites. Polymer, 48, 1005-1011. http://dx.doi.org/10.1016/j.polymer.2006.12.028

[16] Mo, X., Chen, H.Z., Wang, Y., Shi, M.M. and Wang, M. (2005) Fabrication and Photoconductivity Study of Copper Phthalocyanine/Perylene Composite with Bulk Heterojunctions Obtained by Solution Blending. J. Phys. Chem. B, 109, 7659-7663. http://dx.doi.org/10.1021/jp050391+

[17] Mulder, M. (1996) Basic Principles of Membrane Technology. Kluwer Academic Publishers, Dordrecht. http://dx.doi.org/10.1007/978-94-009-1766-8

[18] Yao, W.W., Tan, Y.S., Low, Y.X., Yuen, J.S.Y., Lau, C. and Webster, R.D. (2009) Voltammetrically Controlled Electron Transfer Reactions from Alkanethiol Modified Gold Electrode Surfaces to Low Molecular Weight Molecules Deposited within Lipid (Lecithin) Bilayers. J. Phys. Chem. B, 113, 15263-15271. http://dx.doi.org/10.1021/jp905324q

[19] Tien, H.T. and Ottova, A.L. (1998) Supported Planar Lipid Biolayers (s-BLMs) as Electrochemical Biosensors. Electrochimica Acta, 43, 3587-3610. http://dx.doi.org/10.1016/S0013-4686(98)00107-8

[20] Sandlfer, J.R. (1981) Silver/Silver Chloride Electrodes Coated with Cellulose Acetate for the Elimination of Bromide and Uric Acid Interferences. Anal. Chem., 53, 1164-1170. http://dx.doi.org/10.1021/ac00231a006

[21] Tien, H.T. and Ottova, A.L. (1998) Supported Planar Lipid Biolayers (s-BLMs) as Electrochemical Biosensors. Electrochimica Acta, 43, 3587-3610. http://dx.doi.org/10.1016/S0013-4686(98)00107-8

[22] Thanonkaew, A., Benjakul, S., Visessanguan, W. and Decker, E.A. (2006) Development of Yellow Pigmentation in Squid (Loligo peali) as a Result of Lipid Oxidation. J. Agric. Food Chem., 54, 956-962. http://dx.doi.org/10.1021/jf052107h 